\title{
The apparent retention of food in the reticulo-rumen at two levels of feeding by means of an hourly feeding technique
}

\author{
By D. J. MINSON \\ CSIRO, Cooper Laboratory, Division of Tropical Pastures, \\ Lawes, Queensland, Australia
}

(Received 7 February I966-Accepted 6 fune 1966)

\begin{abstract}
I. Sheep fitted with rumen cannulas were fed at hourly intervals by an automatic feeder in a controlled environment and the contents of the reticulo-rumen were removed at intervals of $6 \mathrm{~h}, 30 \mathrm{~min}$ after the previous feed. 2. No diurnal variation was found in the total contents or in the quantity of dry matter, organic matter and nitrogen. 3. Nine dried pasture herbages containing $0.79-3.69 \% \mathrm{~N}$ in dry matter were given automatically at a high and a low level of feeding. Feeding at the high level increased the total weight of the reticulo-rumen contents, total dry matter, organic matter and $\mathbf{N}$ and also the dry-matter percentage. 4. Appatent retention times were calculated by dividing the quantity of organic matter or $\mathrm{N}$ in the rumen by the quantity given each hour. Organic matter was retained for $10 \cdot 2-24.9 \mathrm{~h}$ and $\mathrm{N}$ for $12 \cdot 0-$ $6 \mathrm{I} \cdot 4 \mathrm{~h}$. 5 . The apparent retention times for both organic matter and $\mathrm{N}$ were reduced when the level of feeding was raised.
\end{abstract}

'It has long been appreciated that a relation might exist between the bulk of food and the amount of it voluntarily eaten by ruminants and that this would probably depend on the filling effect in the gut, and especially in the reticulo-rumen, and hence on such factors as the digestibility and rate of passage of the food' (Balch \& Campling, 1962). Balch (1950) developed a method of estimating the retention times of food in the reticulo-rumen from the rate of excretion in the faeces of stained food particles. However, retention times calculated in this way apply only to the portion of the food that absorbs the stain and appears undigested in the faeces. A more direct approach is to measure the quantity of digesta in the reticulo-rumen. The usual method is to give the feed at intervals of 12 or $24 \mathrm{~h}$ and at various times after the last feed to weigh and analyse the contents of the reticulo-rumen obtained either by killing sample animals (Meyer, Gaskill, Stoewsand \& Weir, 1959) or through a rumen fistula (Kick \& Gerlaugh, 1936; Campling, Freer \& Balch, I961 ; Reid, 1965). Although widely used, the method is laborious and the results are difficult to interpret because of the presence of residues of feeds given before the test feed and probable differences in the retention times of different chemical fractions. A simple method of studying feed retention time could be the use of animals in which the contents of the reticulorumen are maintained in a 'steady state'.

This paper describes a method of measuring apparent retention times of organic matter and nitrogen in the reticulo-rumen and how retention times vary with level of feeding. The sheep were fed at hourly intervals in a controlled environment; this method eliminated diurnal variations in the excretion rate and composition of faeces and urine (Minson \& Cowper, r966). 
The apparent retention times of the fibrous fractions of the rations and the relation between voluntary intake and apparent retention times will be considered in a later paper.

\section{EXPERIMENTAL}

Experimental animals

The experiments were conducted with five two-tooth Merino wethers weighing $35-40 \mathrm{~kg}$ and each fitted with a rumen cannula similar to that described by Watanabe \& Umezu ( 1962$)$. The fistula was sufficiently large to allow the hand to pass easily into the reticulo-rumen when the contents were being removed. The sheep were kept permanently in galvanized iron metabolism crates fitted with wire grid floors through which the urine and faeces fell on to collection trays. No measurements were made of faeces and urine output. To eliminate diurnal variations in light intensity the sheep were kept in a blacked-out room ( $20 \mathrm{ft} \times \mathrm{I}_{4} \mathrm{ft}$ ) continually lit by four $40 \mathrm{~W}$ fluorescent tubes. Temperature was maintained at $25^{\circ}$ with a $\mathrm{I} \cdot 5 \mathrm{hp}$ air-conditioning unit. No attempt was made to eliminate variations in the relative humidity. Diurnal variations in sound level occurring outside the room were masked by the noise from a radio tuned to a $24 \mathrm{~h}$ programme.

Table I. Characteristics of the pasture herbages given to the sheep

\begin{tabular}{|c|c|c|c|c|c|c|}
\hline $\begin{array}{c}\text { Feed } \\
\text { no. }\end{array}$ & Species & Date cut & $\begin{array}{c}\text { Age } \\
\text { (days)* }\end{array}$ & $\begin{array}{c}\text { Dry } \\
\text { matter } \\
(\%)\end{array}$ & $\begin{array}{l}\text { Nitrogen } \\
\text { in dry } \\
\text { matter } \\
(\%)\end{array}$ & $\begin{array}{l}\text { Ash } \\
\text { in dry } \\
\text { matter } \\
(\%)\end{array}$ \\
\hline \multicolumn{7}{|c|}{ Study of diurnal variation } \\
\hline I & Lucerne & r. vi. 65 & 35 & $9 x \cdot 5$ & $3 \cdot 69$ & $9 \cdot 2$ \\
\hline 2 & Lucerne & $\mathrm{NR} \uparrow$ & NR & $89 \cdot 2$ & $3 \cdot 32$ & II 0 \\
\hline \multicolumn{7}{|c|}{ Study of level of feeding } \\
\hline 3 & Pangola & I7. ii. 65 & NR & $88 \cdot 5$ & 0.79 & $8 \cdot 5$ \\
\hline 4 & $\begin{array}{l}\text { Rhodes grass var. } \\
\text { Callide }\end{array}$ & 7. i. 64 & NR & $91 \cdot 7$ & 0.93 & $12 \cdot 3$ \\
\hline 5 & Pangola & I4. iv. 64 & 84 & $90 \cdot 5$ & I'37 & $4 \cdot 0$ \\
\hline 6 & $\begin{array}{l}\text { Rhodes grass var. } \\
\text { Callide }\end{array}$ & 25. ii. 64 & 49 & $89 \cdot 5$ & $I \cdot 43$ & $\mathrm{II} \cdot 2$ \\
\hline 7 & Paspalum-white clover & ii. $6_{5}$ & NR & $89 \cdot 8$ & $I \cdot 50$ & $7 \cdot 5$ \\
\hline 8 & Pangola & 27. ii. 64 & 37 & $90 \cdot 5$ & $I \cdot 9 I$ & $5 \cdot 6$ \\
\hline 9 & $\begin{array}{l}\text { Rhodes grass var. } \\
\text { Samford }\end{array}$ & 26. ii. 64 & 50 & $90 \cdot 2$ & $2 \cdot 17$ & II 9 \\
\hline Io & Paspalum-white clover & xi. 64 & NR & $86 \cdot 8$ & $3 \cdot 20$ & 9.7 \\
\hline I I & Lucerne & I. vi. 65 & 35 & $91 \cdot 5$ & 3.69 & $9 \cdot 2$ \\
\hline
\end{tabular}

\section{Pasture}

The pasture herbages used were Medicago sativa L. (lucerne), Digitaria decumbens Stent (Pangola grass), Chloris gayana Kunth. (Rhodes grass) and Paspalum dilatatum Poir-Trifolium repens L. (paspalum-white clover) (Table I).

Feeds nos. I-3, 7, and 9-II (see Table I) were sun-dried in the field and the remainder artificially dried at a low temperature (drier inlet temperature $85^{\circ}$ ). All 
feeds were chaffed to a length of $\mathrm{I}$ in and offered in the air-dry state. Dried and ground samples of pasture were analysed for $\mathrm{N}$ by the Kjeldahl method, with copper sulphate and selenium as catalysts, and for ash by incineration at $55^{\circ}$.

\section{Feeding regime}

All herbages tested were given in equal and known quantities every hour (on the hour) for 7 days before emptying the reticulo-rumen. An automatic feeder fixed above the metabolism crates was used to deliver the previously weighed feed into bins in front of the sheep (Minson \& Cowper, 1966). The machine was refilled at $08.00 \mathrm{~h}$ every day, except in the two studies of diurnal variations, when it was refilled $24 \mathrm{~h}$ before the reticulo-rumen contents were removed.

To study diurnal variations in the reticulo-rumen contents two experiments were conducted with two sheep. In Expts I and 2, 34.8 and $33.9 \mathrm{~g}$ lucerne dry matter were given each hour for 4 weeks. The reticulo-rumens were emptied at approximately $09.00,15.00,21.00$ and $03.00 \mathrm{~h}$ on the last day of the 4 weeks. The remaining experiments were designed to study the effect of level of feeding on retention time. Each feed was given to the same sheep at two levels: a level as high as possible without any being refused at any time and a low level when approximately half this quantity was given (Table 4). No measurements of reticulo-rumen contents were made if any feed was refused. Drinking water and a commercial mineral mixture containing trace elements and salt were available to the sheep at all times.

\section{Emptying procedure}

The sheep was walked from the controlled environment room, $30 \mathrm{~min}$ after the last feed, placed right side down on a hinged table top and tied down by the feet and neck. The back rested against a board 12 in wide fixed at right angles to the edge of the table. In this board a $U$-shaped gap $\mathrm{I} 2$ in wide and 6 in deep had been cut directly in line with the rumen fistula. The hinged table top was then turned upwards through $75^{\circ}$ so that the sheep lay on its back against the board. A plastic bucket was placed against the sheep; the cannula was removed and the liquid contents of the reticulorumen flowed into the bucket. The solid material was removed by hand. The quantity of digesta left in the reticulo-rumen was so small that washing out was not necessary.

The entire contents of the reticulo-rumen were weighed and mixed with an electric mixer, and three $500 \mathrm{~g}$ (approx.) samples taken for dry-matter determination at $100^{\circ}$ and subsequent determination of ash. Another sample was mixed in a high-speed blender, and two samples were taken for total $\mathrm{N}$ determination by the Kjeldahl method. The remainder of the reticulo-rumen contents was returned to the sheep. The procedure took two people $20 \mathrm{~min}$ to complete and the sheep suffered no apparent discomfort.

\section{Calculation of apparent retention time}

Apparent retention times for organic matter and $\mathrm{N}$ in the reticulo-rumen were calculated for the nine feeds given at each level. In this paper apparent retention time 
is defined as the average time a chemical component in the ration remains in the reticulo-rumen and was calculated as:

$$
\text { Apparent retention time }(\mathrm{h})=\frac{\text { weight of component in the rumen }}{\text { weight of component given each hour }} \text {. }
$$

Owing to the flow of saliva into the reticulo-rumen and the passage of certain components through the wall of the reticulo-rumen, all retention times were apparent and not absolute values for the feed.

\section{RESULTS}

\section{Diurnal variation}

Expt I. In the first study of diurnal variations one sheep refused to eat all the lucerne offered on the $27^{\text {th }}$ day of the experiment and results are, therefore, available for only the first three emptying times. For convenience, results are given for the mean emptying time and not the actual times, which were $30 \mathrm{~min}$ before or after this time.

The weight of the total contents of the reticulo-rumen varied both between sheep and between sampling times, but the variation appeared to have no consistent pattern (Table 2). No consistent differences occurred in the quantity of dry matter, $N$ or ash between the different sampling times, but there was a consistent trend for sheep 68 to retain lower quantities of these components than sheep i 16 (Table 2).

Mean apparent retention times for the two sheep for organic matter and $\mathrm{N}$ are given in Table 3. These obviously followed the same pattern as the total quantities retained but the apparent retention times for organic matter were shorter than those for $\mathrm{N}$.

Expt 2. The results obtained in the second study of diurnal variations show that the quality of material in the reticulo-rumen was variable, but there was no indication of a diurnal rhythm (Table 2). The high dry-matter content of the reticulo-rumen of sheep $5^{8}$ at $03.00 \mathrm{~h}$ was associated with a high ash content, possibly caused by a high intake of the mineral mixture which was always on offer. As in the first experiment, there appeared to be a difference between animals in the quantity of dry matter, $\mathrm{N}$ and ash retained in the rumen. The mean apparent retention times of the organic matter and $\mathrm{N}$ were longer than in the first experiment (Table 3 ).

\section{Level of feeding}

Total contents. The total weight of the reticulo-rumen contents varied between feeds (Table 4) but this effect may be confounded with differences among the three sheep used. With all feeds, except no. 4 , an increase in the quantity of feed led to a rise in the total content of the reticulo-rumen.

Dry matter. An increase in the level of feeding always resulted in an increase in the dry-matter concentration in the reticulo-rumen contents. Owing to the increase in both total contents of the reticulo-rumen and dry-matter concentration with increasing level of feeding, the total dry matter present was also increased (Table 4). 


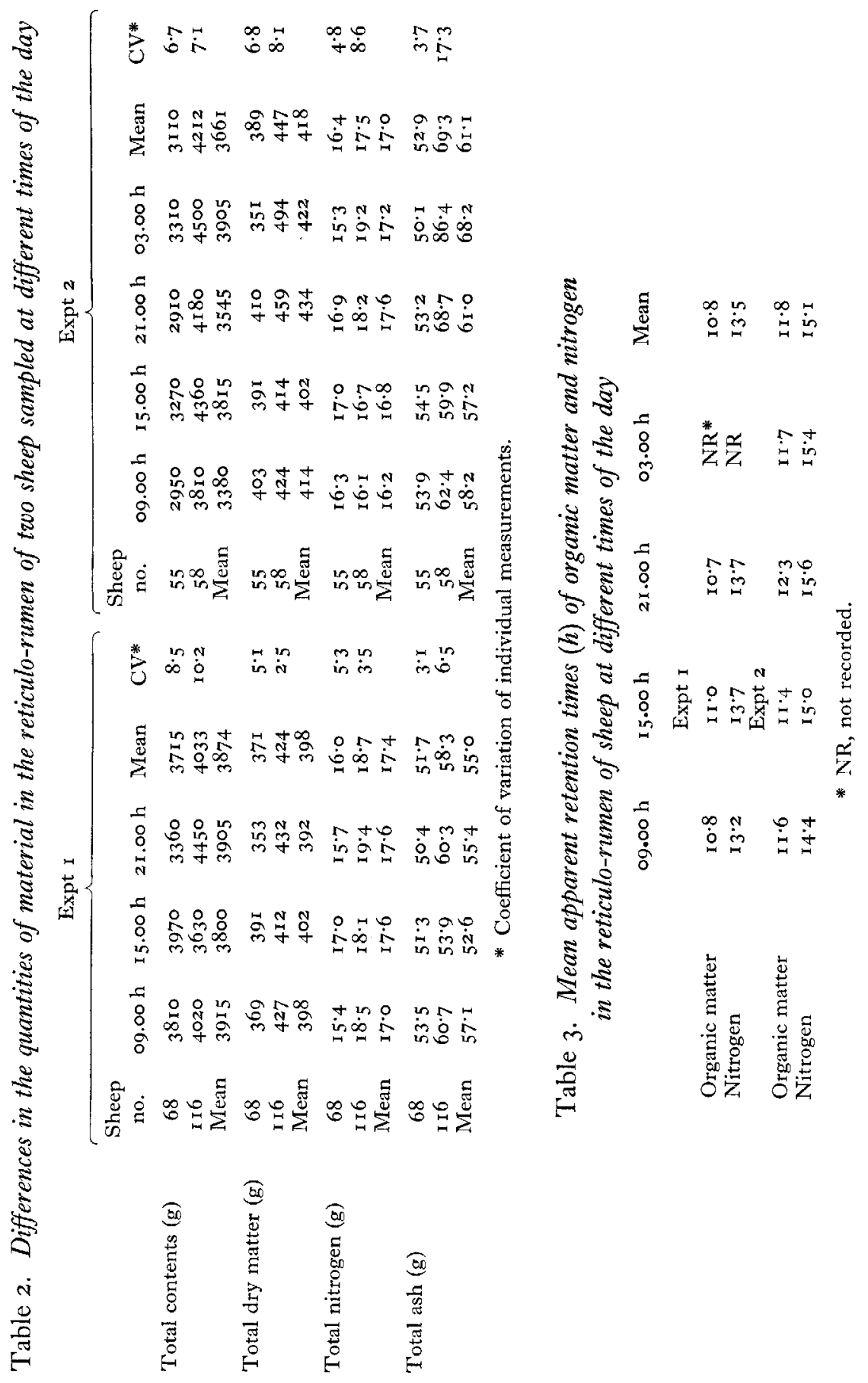




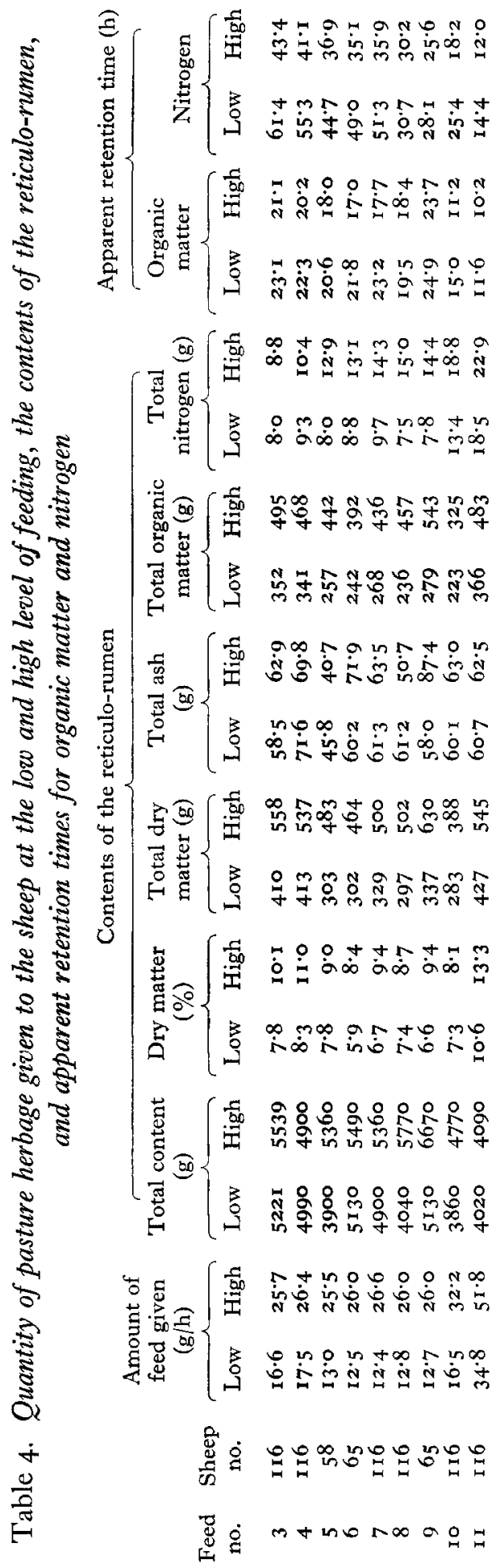


Ash. The ash percentage of the dry matter in the reticulo-rumen was lowest when the feed was given at the high level. The total quantity of ash present showed no consistent trend in relation to level of feeding. With six of the nine feeds the largest quantity of ash was found with the high level of feeding but the difference between values at the two levels was often small (Table 4 ).

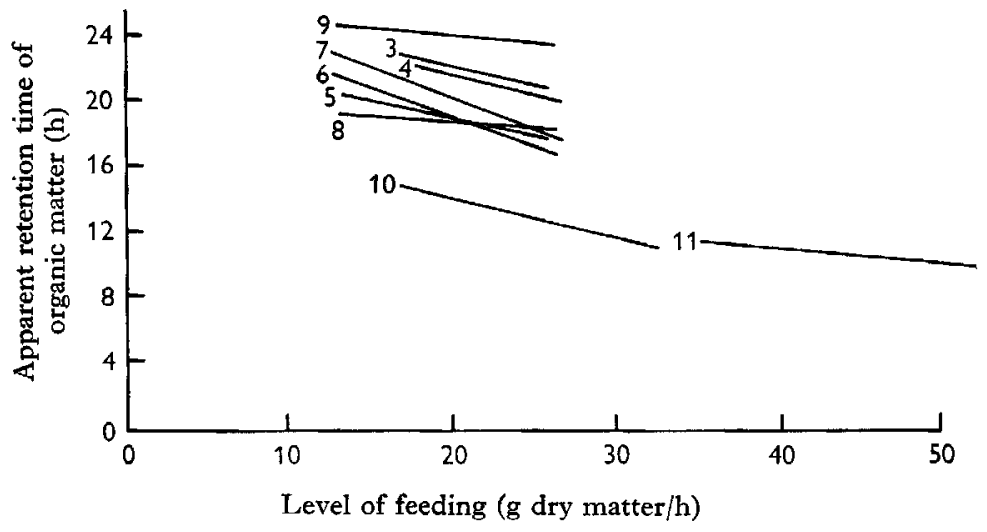

Fig. I. Apparent retention time of organic matter in the reticulo-rumen of sheep as affected by level of feeding. The number by each line indicates the feed given (see Table I).

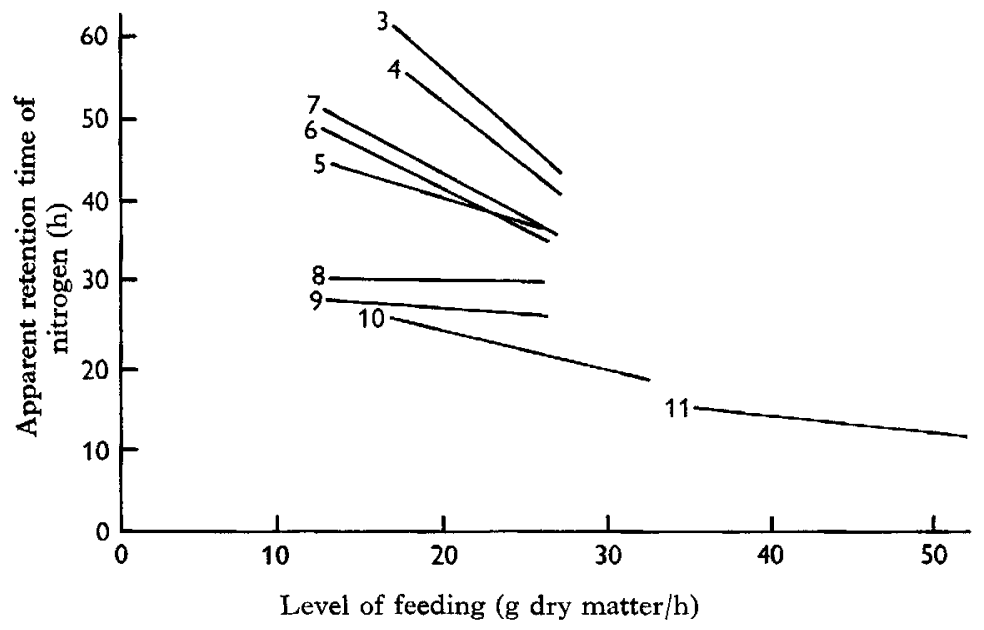

Fig. 2. Apparent retention time of nitrogen in the reticulo-rumen of sheep as affected by level of feeding. The number by each line indicates the feed given (see Table I).

Organic matter. The largest quantity of organic matter in the reticulo-rumen was found with the high level of feeding (Table 4). When apparent retention times for the organic matter were calculated, it was found that the shortest retention times were associated with the high level of feeding (Fig. I).

Nitrogen. The total quantity of $\mathrm{N}$ in the reticulo-rumen was highest with the high level of feeding. The quantity of $\mathrm{N}$ varied between 8.0 and 22.9 $\mathrm{g}$ and this variation was associated with the total quantity of $\mathrm{N}$ ingested each hour. Apparent retention 
times for $\mathrm{N}$ were shortest with the high level of feeding and varied between $12 \cdot 0$ and $6 \mathrm{I}^{\circ} 4 \mathrm{~h}$ (Fig. 2). Differences in apparent retention time were related to the quantity of $\mathrm{N}$ ingested each hour (Fig. 3).

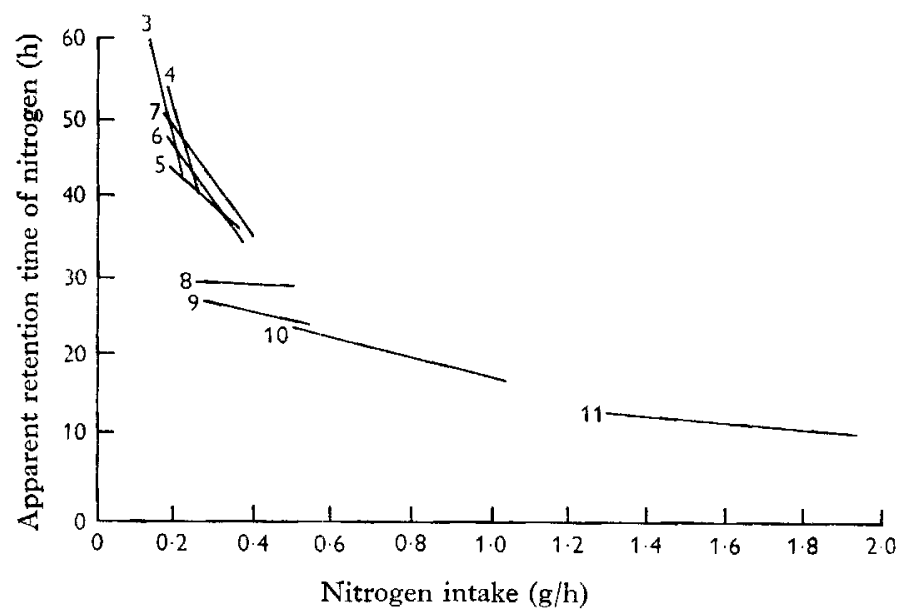

Fig. 3. Apparent retention time of nitrogen in the reticulo-rumen of sheep as affected by the nitrogen intake. The number by each line indicates the pasture given (see Table I).

\section{DISCUSSION}

The two experiments in which the reticulo-rumens were emptied at various times of the day and night gave no indication of diurnal variations in the weight of the total contents or the quantity of dry matter, organic matter and $N$ when sheep were automatically fed at hourly intervals in a controlled environment. This technique, therefore, appears to be a satisfactory method of studying factors affecting the apparent retention of food in the reticulo-rumen. The value of the technique depends on the repeatability of any measurement. From the results obtained in Expts $\mathrm{I}$ and 2 the coefficient of variation of individual determinations of total contents, dry matter, $\mathrm{N}$ and ash were calculated for each sheep (Table 2). With the exception of ash content, the coefficient of variation for all measurements was less than $10 \cdot 2 \%$ and was as low as $2.5 \%$ for the dry matter in the reticulo-rumen of sheep I 16 .

When the level of feeding was raised there was usually an increase in the total weight of the rumen contents and the quantity of dry matter, organic matter and $\mathrm{N}$. The lack of a consistent pattern in the ash content was probably associated with variations in the consumption of the mineral mixture that was offered ad lib. The rumen contents sometimes contained large quantities of this mixture. To overcome any bias caused by variations in the consumption of the mineral mixture, apparent retention times were calculated for organic matter and not for dry matter.

The apparent retention time of the organic matter in the reticulo-rumen decreased when the level of feeding was raised. This result, based on a direct measurement of apparent retention time, is in agreement with the results of Blaxter, Graham \& Wainman (1956), who used an indirect method based on the excretion curves of stained 
grass particles in the faeces. The decrease in the apparent retention time of organic matter is probably a factor causing the depression in digestibility of organic matter with rising level of feeding (Blaxter \& Graham, 1956; Raymond, Minson \& Harris, I959).

The apparent retention times for the $\mathrm{N}$ in all nine feeds were longer than the corresponding times for the organic matter. With Pangola, containing $0.79 \% \mathrm{~N}$ in the dry matter, the $\mathrm{N}$ retention time was twice that of the organic matter, but for lucerne containing $3.69 \% \mathrm{~N}$ the difference was small. The long apparent retention times for $\mathrm{N}$ were not expected, and this observation is difficult to explain. One possibility is the addition to the reticulo-rumen of $\mathrm{N}$ in the saliva (McDonald, 1948). However, Bailey \& Balch (I96r) found large variations in the urea concentration in saliva owing to variations in the amount of ammonia produced in the rumen, and this would be positively correlated with the $\mathrm{N}$ percentage of the feed. Since the apparent retention times for $\mathrm{N}$ were longest when the smallest addition of saliva $\mathrm{N}$ might have been expected, it appears unlikely that saliva $\mathrm{N}$ was the cause of the long apparent retention times on low- $\mathrm{N}$ feed. A second and more probable reason is that the small quantity of $\mathrm{N}$ in the feed was rapidly utilized by the bacteria breaking down the cellulose in the feed and therefore it had a retention time similar to that of the less rapidly digested portion of the feed to which the bacteria would be attached (Schwartz, Schoeman \& Färber, 1964). Further work is required before the mechanism controlling the apparent retention time of $\mathrm{N}$ in the reticulo-rumen is understood.

My thanks are due to Miss A. Hoxey, who was responsible for the daily maintenance of the sheep, and to $\mathrm{Mr} \mathrm{H}$. J. Kiers and the Plant Chemistry staff of the CSIRO, Cunningham Laboratory, Brisbane, for chemical analysis. I also thank Mr L. G. Andrews, BVSc, Lecturer in Animal Husbandry at the Queensland Agricultural College, Lawes, for fitting the rumen cannulas and Dr R. Milford, officer-in-charge of the Cooper Laboratory, for encouraging this work.

\section{REFERENCES}

Bailey, C. B. \& Balch, C. C. (I96I). Br. F. Nutr. 15, $3^{83}$.

Balch, C. C. (1950). Br. $¥$. Nutr. 4, 36r.

Balch, C. C. \& Campling, R. C. (1962). Nutr. Abstr. Rev. 32, 669.

Blaxter, K. L. \& Graham, N. McC. (1956). F. agric. Sci., Camb. 47, 207.

Blaxter, K. L., Graham, N. McC. \& Wainman, F. W. (1956). Br. F. Nutr. 1o, 69.

Campling, R. C., Freer, M. \& Balch, C. C. (1961). Br. J. Nutr. 15, 531.

Kick, C. H. \& Gerlaugh, P. (1936). Proc. Am. Soc. Anim. Prod. 28, 93.

McDonald, I. W. (1948). Biochem. F. 42, 584.

Meyer, J. H., Gaskill, R. L., Stoewsand, G. S. \& Weir, W. C. (1959). F. Anim. Sci. 18, 336.

Minson, D. J. \& Cowper, J. L. (1966). Br. F. Nutr. 20, 757.

Raymond, W. F., Minson, D. J. \& Harris, C. E. (1959). F. Br. Grassld Soc. 14, 75.

Reid, C. S. W. (1965). Proc. N.Z. Soc. Anim. Prod. 25, 65.

Schwartz, H. M., Schoeman, C. A. \& Färber, M. S. (1964). F. agric. Sci., Camb. 63, 289.

Watanabe, Y. \& Umezu, M. (1962). Tohoku F. agric. Res. 13, 221. 